\title{
Short communication: A genetic study of mortality in Danish Jersey heifer calves
}

\author{
E. Norberg, ${ }^{\star 1}$ J. E. Pryce, $† \ddagger$ and J. Pedersen§ \\ ${ }^{*}$ Centre for Quantitative Genetics and Genomics, Department of Molecular Biology and Genetics, Faculty of Science and Technology, \\ Aarhus University, PO Box 50, DK-8830 Tjele, Denmark \\ †Biosciences Research Division, Department of Primary Industries Victoria, AgrioBio, 5 Ring Road, Bundoora, VIC 3083, Australia \\ $\ddagger$ Dairy Futures Cooperative Research Centre, 1 Park Drive, Bundoora, VIC 3083, Australia \\ §Knowledge Centre for Agriculture, AgroFoodPark 15, 8200 Aarhus N, Denmark
}

\section{ABSTRACT}

The aim of this study was to estimate genetic parameters for mortality of Jersey heifer calves during the first 6 mo after birth, calculate the genetic trend of the trait, and estimate breeding values of widely used Jersey sires. More than 260,000 heifer calves were included in the study. The mortality traits included in the analysis were defined as mortality in 8 different periods from $24 \mathrm{~h}$ after birth to age $180 \mathrm{~d}$ (d 1-14, d 15-30, d 31-60, d 61-90, d 91-120, d 121-150, and d 151-180) and mortality over the entire period. A linear model was used for estimation of genetic parameters, breeding values of sires, and genetic trend. Fixed effects included in the model were herd-year class, month of birth, parity of mother, and whether the calf was sold to another farm in the first 6 mo. Both direct and maternal genetic effects were included in the model; however, the maternal genetic effect was very small and not significant. The mortality rate was highest in the first month after birth $(7.8 \%)$. Total mortality in the first $180 \mathrm{~d}$ was $12.5 \%$. Direct heritabilities of mortality were quite low, ranging from 0.002 to 0.03 on the observable scale and 0.025 to 0.076 on the underlying scale. Maternal heritabilities were even lower. The genetic correlation between mortality from d 1 to 14 and d 1 to 180 was estimated to be 0.88 , although by definition, these 2 traits share the same observations for many records. No clear genetic trend existed over the last $20 \mathrm{yr}$; however, considerable genetic variation exists. The best and the worst sires differed by about $8 \%$ in their estimated breeding values of mortality in the first $180 \mathrm{~d}$. Based on the results obtained in this study, genetic selection for reducing calf mortality should be possible.

Key words: mortality, Jersey calf, genetic parameter, breeding value

Received April 25, 2012.

Accepted March 6, 2013.

${ }^{1}$ Corresponding author: elise.norberg@agrsci.dk

\section{Short Communication}

In recent years there has been increasing focus on the mortality of dairy cattle. In several breeds, mortality rates of cows have increased (McConnel et al., 2008), as well as stillbirth and prepubertal mortality of calves. This is not only a problem of economic importance, but also a major ethical issue. A few studies have investigated the genetic background of prepubertal mortality in dairy calves (Erf et al., 1990; Hansen et al., 2003; Fuerst-Waltl and Sørensen, 2010; Henderson et al., 2011; Van Pelt and De Jong, 2012). In Denmark, field records of mortality have been available for all Danish cattle over the last $20 \mathrm{yr}$. Newborn calves from the Jersey breed are known to have high mortality rates. The high frequency of mortality is partially explained by the common practice of euthanizing young male calves. However, mortality of Danish Jersey heifer calves has been reported to be around 12 to $13 \%$. The comparable frequency of prepubertal mortality in the Danish Holstein and Danish Red breeds is 5 to $6 \%$ and 6 to $7 \%$, respectively. Therefore, it appears that mortality is more of a problem in Jerseys than other dairy breeds. Hansen et al. (2003) found that heritabilities of prepubertal mortality in Danish Holstein were very low $(<0.01)$. However, these estimates were affected by the relatively low frequency of mortality in their study (6.6\%). No genetic parameters have been published on prepubertal mortality in Jerseys. The aim of this study was, therefore, to estimate genetic parameters for mortality from $24 \mathrm{~h}$ after birth to $180 \mathrm{~d}$ in Danish Jersey heifer calves. Previous studies have shown that the maternal genetic effects are considerable for stillbirth (Weller and Gianola, 1989; Steinbock et al., 2003; Hansen et al., 2004). Therefore, both direct and maternal additive genetic parameters for mortality were estimated in this study. Finally, breeding values of sires and genetic trends were calculated.

Records on all Danish Jersey heifer calves born from January 1998 to December 2006 that survived $24 \mathrm{~h}$ after birth were extracted from the Danish Cattle Database. 
Information on calving, transfers to other farms, death, and slaughter were available on all animals. Calves from herds with fewer than 100 records during the time period and records of twins and triplets were omitted from the study. The final data set consisted of 262,089 records. Pedigree was traced back as far as possible. Eight mortality traits were defined based on mortality in different periods: $\mathrm{d} 1$ to 14 , d 15 to $30, \mathrm{~d} 31$ to $60, \mathrm{~d}$ 61 to 90 , d 91 to 120 , d 121 to 150 , d 151 to 180 , and d 1 to 180 . Mortality in the defined periods included only mortality between the given days after birth, and not mortality until the given period. The model included a transfer code to account for a possible negative effect of moving calves between herds. Calves that were not transferred in the first $180 \mathrm{~d}$ were assigned to one group and calves that were transferred from d 14 to 30 were assigned to a second group (calves younger than $2 \mathrm{wk}$ of age are not allowed to be transported in Denmark). Finally, calves transferred between d 31 and 180 were assigned to a third group. Transferring of calves in the first $180 \mathrm{~d}$ of life was rare, only $0.49 \%$ were moved between d 14 and 30 , and $0.16 \%$ were moved between d 31 and 180. However, mortality rates were higher for transferred calves: 16.5 and $44.4 \%$ for calves transferred between d 14 and 30 and between d 31 and 180, respectively.

As estimating both direct and maternal genetic effects with a threshold model was not possible with the software used in this study, a linear animal model was used for estimation of all (co)variance components. Effects included in the model were as follows:

$$
\begin{gathered}
\mathrm{M}_{\mathrm{ijklmn}}=\mathrm{HY}_{\mathrm{i}}+\mathrm{BM}_{\mathrm{j}}+\mathrm{PM}_{\mathrm{k}}+\mathrm{TG}_{\mathrm{l}} \\
+\mathrm{adir}_{\mathrm{m}}+\mathrm{amat}_{\mathrm{n}}+\mathrm{e}_{\mathrm{ijklmn}},
\end{gathered}
$$

where $\mathrm{M}_{\mathrm{ijklmn}}=$ prepubertal mortality, $\mathrm{HY}_{\mathrm{i}}=$ fixed effect of herd-year class, $\mathrm{BM}_{\mathrm{j}}=$ fixed effect of month of birth $(1,2,3, \ldots, 12), \mathrm{PM}_{\mathrm{k}}=$ fixed effect of parity of the mother $(1,2, \ldots, 5), \mathrm{TG}_{1}=$ fixed effect of transfer group (1, 2, or 3$)$, adir ${ }_{\mathrm{m}}=$ random direct additive genetic effect of animal $o$, amat $t_{\mathrm{n}}=$ random maternal additive genetic effect of animal $p$, and $\mathrm{e}_{\mathrm{ijk} k \mathrm{mn}}=$ random residual.

In addition, the direct genetic correlation between mortality from d 1 to 14 and d 1 to 180 was estimated using a bivariate analysis; however, the maternal genetic effect was excluded due to computational limitations. For estimation of the genetic trend and breeding values of sires, a sire model was used. The same data set was analyzed and the same fixed effects were included in this model. All analyses in this study were carried out with the AI-REML algorithm using the DMU package (Madsen and Jensen, 2010). The convergence criterion used was a change in the norm of the update vector less than $10^{-5}$. Heritabilities were transformed to the underlying scale by the approximate formula proposed by Dempster and Lerner (1950).

In Figure 1, the mean mortality for each of the 8 defined periods is presented. Mortality over the entire period (i.e., from d 1 to 180 ) was $12.5 \%$. Mortality was highest in the first month after birth (7.8\%). All fixed effects had a significant effect on mortality in all time periods. The risk of mortality increased with increasing parity of mother, which is in contradiction to what was found in Norwegian Red cattle (Gulliksen et al. 2009). Calves born in the winter period had a higher risk of dying than calves born in the spring and summer, and this result agrees well with the results reported by Gulliksen et al. (2009).

Phenotypic standard deviations, direct and maternal additive genetic variances, and direct and maternal heritabilities of mortality in the different periods after birth are presented in Table 1. The direct heritability was largest, both on the observed scale (0.029) and the underlying scale (0.076), when estimated on data from the entire period (i.e., from d 1 to 180). All direct heritabilities of the mortality traits analyzed were significant. Hansen et al. (2003) estimated direct heritabilities for prepubertal mortality in Danish Holstein heifers and they found direct heritabilities of mortality from d 1 to 14 and from $d 1$ to 180 on the observable scale to be 0.0033 and 0.0061 , respectively, and on the underlying scale to be 0.024 and 0.025 . The results reported here and by Hansen et al. (2003) correspond well with what presented for Brown Swiss by Erf et al. (1990), who found a direct heritability of 0.008 on the observable scale for early mortality (d 1 to 7 ). In the study on heifer loss in the total replacement period for Danish Holstein by Fuerst-Waltl and Sørensen (2010), heritabilities in early life (1-30 d after birth and 30-180 d after birth) were estimated to be 0.017 and 0.022 , respectively, with a linear model and 0.082 and 0.001 with a threshold model. Henderson et al. (2011) found a very small heritability (0.0006) for mortality from $\mathrm{d}$ 1 to weaning when applying a linear model. Another recent study on Holstein calves by Van Pelt and De Jong (2012) reported heritabilities for mortality from d 3 to 365 to be 0.011 on the observable scale and 0.040 on the underlying scale, whereas the heritability from d 15 to 30 was 0.001 on the observable scale. Based on those studies, heritabilities of prepubertal mortality seem to be higher in Jersey than in the other dairy breeds, at least when presented on the observable scale. Some of the difference may be explained by the higher frequency of prepubertal mortality in Jerseys, as heritabilities of binary traits depend on the frequency. 


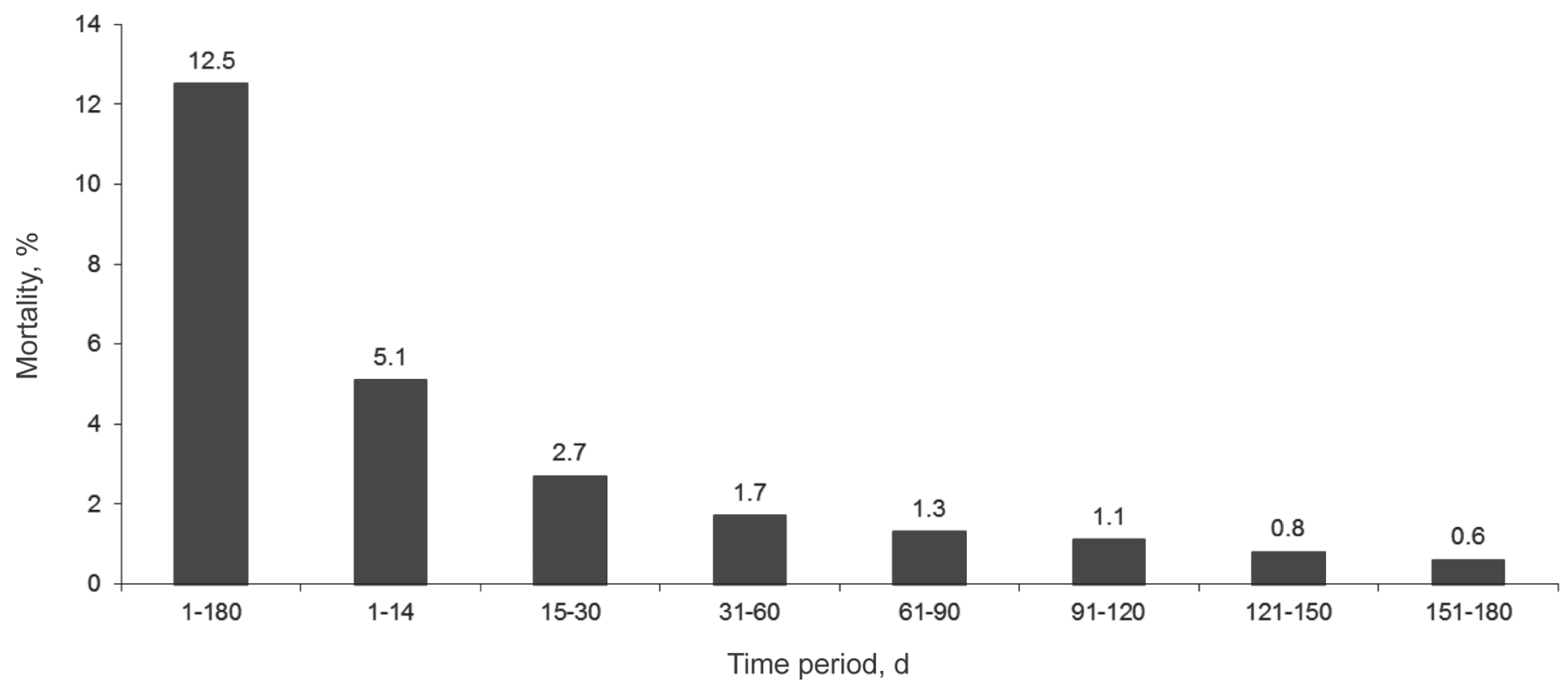

Figure 1. Mortality of Danish Jersey heifer calves in different time periods after birth.

Due to the relatively high frequency and the low heritability of mortality in this study, the approximation proposed by A. Robertson in Dempster and Lerner (1950) should be appropriate. McGuirk et al. (1999) remarked that whereas threshold models may be useful in more unbalanced data sets with widely different incidences across fixed effects (e.g., contemporary groups), they may only offer small advantages in well-designed progeny testing programs with large numbers of records per sire, which is the case in our study. Furthermore, Pryce et al. (2006) and Fuerst-Waltl and Sørensen (2010) showed that for stillbirth and prepubertal mortality, rank correlations between breeding values estimated with a linear model and a threshold model were very high. So, for practical purposes, a linear model is probably sufficient for analyzing this trait. The genetic correlation between mortality from d 1 to 14 and $\mathrm{d} 1$ to 180 was estimated to be 0.88 . However, as survival at $\mathrm{d}$
180 is conditional on survival from d 1 to 14 , we expect a large positive correlation between these 2 traits. A high correlation between early and late mortality (from d 3 to 14 and d 3 to 365) was also found by Van Pelt and De Jong (2012). Goyache et al. (2003) presented a direct genetic correlation between preweaning survival and late mortality of calves of 0.75 and between preweaning and weaning survival of 0.95 . Based on the high genetic correlation and the larger genetic variation for weaning survival than preweaning survival, they suggested including weaning survival in the breeding goal. In our study, the heritability of prepubertal mortality was largest in early life, whereas the genetic variation was largest for the total period (d 1 to 180). Maternal heritabilities of mortality estimated in our study were very small, ranging from 0.00009 to 0.00128 , and were not significant, implying that the dam's role in calf mortality was genetically less important than the direct

Table 1. Phenotypic standard deviation $\left(\sigma_{\mathrm{p}}\right)$, direct additive genetic variance $\left(\sigma_{\mathrm{d}}^{2}\right)$, maternal genetic variance $\left(\sigma_{\mathrm{m}}^{2}\right)$, estimated direct heritabilities $\left(\operatorname{dir} \mathrm{h}_{\text {linear }}^{2}\right)$, direct heritabilities transformed to the underlying continuous scale $\left(\right.$ dir $\left.\mathrm{h}_{\text {trans }}^{2}\right)$, and maternal heritabilities $\left(\right.$ mat $\left.\mathrm{h}_{\text {linear }}^{2}\right)$ of mortality in different periods after birth

\begin{tabular}{lcccccc}
\hline Days from birth & $\sigma_{\mathrm{p}}$ & $\sigma_{\mathrm{d}}^{2}$ & $\sigma_{\mathrm{m}}^{2}$ & $\operatorname{dir} \mathrm{h}_{\text {linear }}^{2}$ & $\operatorname{dir} \mathrm{h}_{\text {trans }}^{2}$ & ${\operatorname{mat~} \mathrm{h}_{\text {linear }}^{2}}^{2}$ \\
\hline $1-180$ & 0.330 & 0.002930 & 0.0002725 & 0.0298 & 0.0766 & 0.00081 \\
$1-14$ & 0.219 & 0.000896 & 0.0000575 & 0.0205 & 0.0965 & 0.00132 \\
$15-30$ & 0.161 & 0.000177 & 0.0000129 & 0.0071 & 0.0507 & 0.00051 \\
$31-60$ & 0.129 & 0.000062 & 0.0000010 & 0.0037 & 0.0385 & 0.00006 \\
$61-90$ & 0.110 & 0.000043 & 0.0000037 & 0.0035 & 0.0251 & 0.00031 \\
$91-120$ & 0.104 & 0.000020 & 0.0000010 & 0.0018 & 0.0259 & 0.00001 \\
$121-150$ & 0.089 & 0.000023 & 0.0000002 & 0.0030 & 0.0446 & 0.00003 \\
$151-180$ & 0.077 & 0.000011 & 0.0000007 & 0.0018 & 0.0495 & 0.00019 \\
\hline
\end{tabular}


Table 2. Frequency of calf mortality between d 1 and 180 after birth and breeding values (BV) for the 5 Danish Jersey sires with the most and least favorable BV for mortality between d 1 and 180

\begin{tabular}{lcc}
\hline Sire & $\begin{array}{c}\text { Frequency of } \\
\text { dead calves, } \%\end{array}$ & $\begin{array}{c}\text { BV prepubertal } \\
\text { mortality, } \%\end{array}$ \\
\hline The 5 sires with the best BV for prepubertal mortality & & \\
1 & 4.7 & 9.40 \\
2 & 9.6 & 9.41 \\
3 & 9.9 & 9.54 \\
4 & 5.3 & 10.03 \\
5 & 9.7 & 10.03 \\
The 5 sires with the worst BV for prepubertal mortality & & \\
10 & 26.6 & 17.51 \\
11 & 19.7 & 17.47 \\
13 & 24.2 & 17.31 \\
14 & 15.0 & 17.14 \\
& 18.5 & 16.35 \\
\hline
\end{tabular}

effect. This is in agreement with early mortality in beef cattle reported by Goyache et al. (2003).

Breeding values $(\mathbf{B V})$ of sires for mortality from d 1 to 180 from 1985 to 2005 are presented in Figure 2. It can be seen that the genetic trend shows no clear deterioration in mortality over this time period, although from 1996 to 2000 an unfavorable genetic trend appeared, which could have been due to a few sires that were widely used in those years. Similarly, the rapid favorable decrease between 2001 and 2004 may be due to the sire with the best $\mathrm{BV}$ for mortality being one of the most frequently used sires in Denmark in the time period. In Table 2 , the 5 sires with the best and worst BV for mortality from d 1 to 180 are presented (a low BV is favorable and vice versa). All the sires ranked had more than 100 heifer offspring. Sire 1 had the lowest BV for mortality and only $4.7 \%$ of the calves of this sire died during the first $180 \mathrm{~d}$. Sire 10 had the highest BV for mortality and a phenotypic mortality rate of $26.6 \%$. The best and the worst sire differed by more than $8 \%$ in BV. Both of these sires had more than 1,000 progeny.

To conclude, the highest incidence of prepubertal mortality in Danish Jersey calves was in the first period after birth. Direct heritabilities were small; however, they were larger than what have previously been reported for other breeds. Maternal heritabilities were very small and not significant. No clear genetic

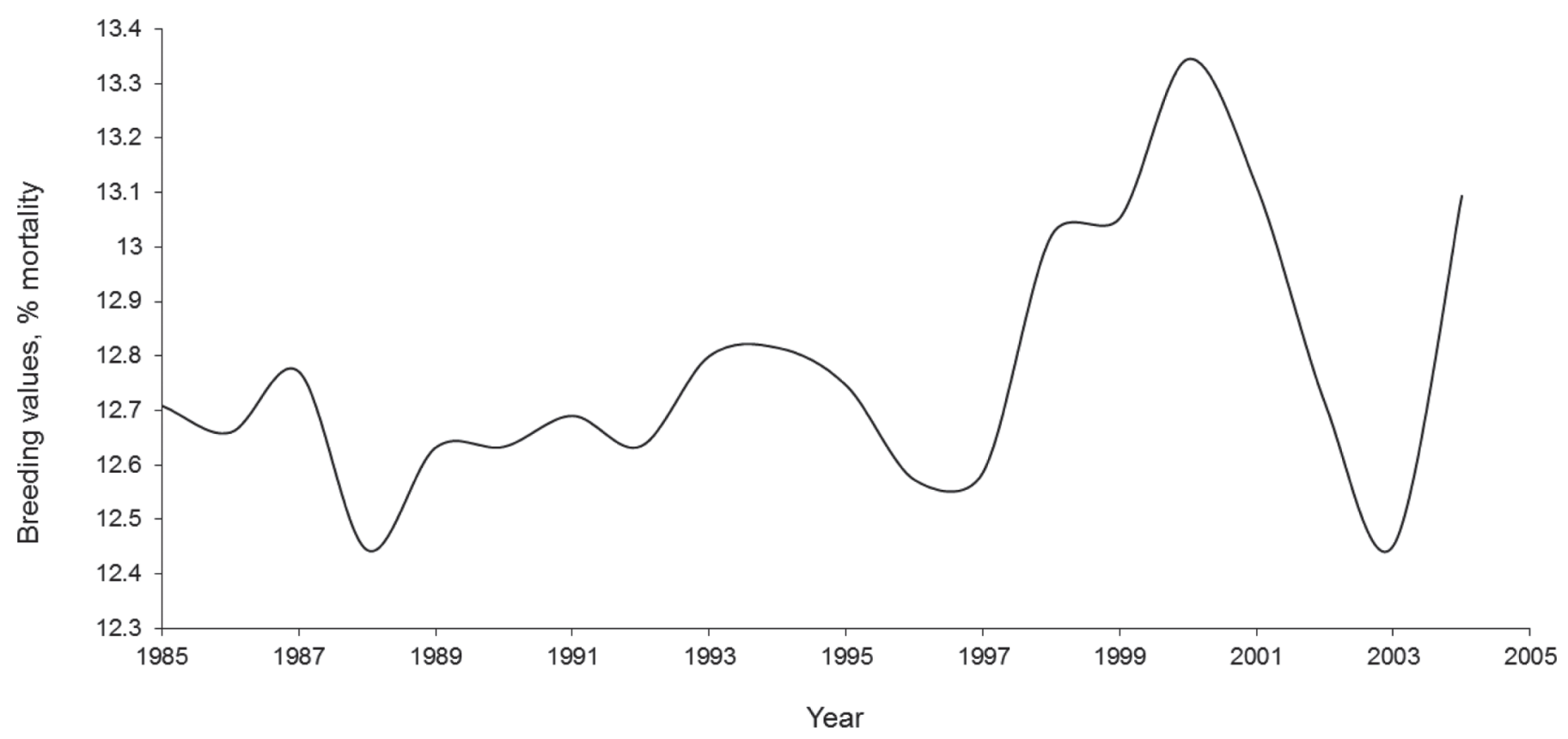

Figure 2. Trend in breeding values for mortality of Jersey heifer calves between d 1 and 180 from 1985 to 2005 for Danish Jersey sires, where year corresponds to the birth year of the sire. 
trend was observed in the BV of sires. Even if the estimated genetic variation of prepubertal mortality was relatively small, a large difference existed between the sires with highest and lowest BV. Due to the relatively high genetic correlation between very early and later prepubertal mortality, and the fact that mortality in the last part of the period analyzed showed the largest genetic variation, we suggest considering this trait in the breeding goal. Based on the results obtained in this study, genetic selection for reduced prepubertal mortality should be possible. Due to the high mortality of Jersey heifer calves and the high genetic correlation between mortality from d 1 to 14 and from d 1 to 180 , BV for mortality during the first 6 mo should be estimated and the trait should be considered for inclusion in the breeding goal.

\section{REFERENCES}

Dempster, E. R., and I. M. Lerner. 1950. Heritability of threshold characters. Genetics 35:212-236.

Erf, D. F., L. B. Hansen, and R. R. Neitzel. 1990. Inheritance of calf mortality of Brown Swiss cattle. J. Dairy Sci. 73:1130-1134.

Fuerst-Waltl, B., and M. K. Sørensen. 2010. Genetic analysis of calf and heifer losses in Danish Holstein. J. Dairy Sci. 93:5436-5442.

Goyache, F., J. P. Gutiérrez, I. Alvarez, I. Fernández, L. J. Royo, and E. Gómez. 2003. Genetic analysis of calf survival at different preweaning ages in beef cattle. Livest. Prod. Sci. 83:13-20.
Gulliksen, S. M., K. I. Lie, T. Løken, and O. Østerås. 2009. Calf mortality in Norwegian dairy herds. J. Dairy Sci. 92:2782-2795.

Hansen, M., M. S. Lund, J. Pedersen, and L. G. Christensen. 2004. Genetic parameters for stillbirth in Danish Holstein cows using a Bayesian threshold model. J. Dairy Sci. 87:706-716.

Hansen, M., P. Madsen, J. Jensen, J. Pedersen, and L. G. Christensen. 2003. Genetic parameters of postnatal mortality in Danish Holstein calves. J. Dairy Sci. 86:1807-1817.

Henderson, L., F. Miglior, A. Sewalem, D. Kelton, A. Robinson, and K. E. Leslie. 2011. Estimations of genetic parameters for measures of calf survival in a population of Holstein heifers calves from a heifer-raising facility in New York State. J. Dairy Sci. 94:461-470.

Madsen, P., and J. Jensen. 2010. A user's guide to DMU. A package for analysing multivariate mixed models. Version 6, release 5.0. Danish Institute of Agricultural Sciences. Tjele, Denmark. Accessed Jan. 2012. http://www.dmu.agrsci.dk/dmuv6_guide.5.0.pdf.

McConnel, C. S., J. E. Lombard, B. A. Wagner, and F. B. Garry. 2008. Evaluation of factors associated with increased cow mortality on United States dairy operations. J. Dairy Sci. 91:1423-1432.

McGuirk, B. J., I. Going, and A. R. Gilmour. 1999. The genetic evaluation of UK Holstein Friesian sires for calving ease and related traits. Anim. Sci. 68:413-420.

Pryce, J. E., B. L. Harris, S. Sim, and A. W. McPherson. 2006. Genetics of stillbirth in dairy calves. Proc. N.Z. Soc. Anim. Prod. 66:98-102.

Steinbock, L., A. Näsholm, B. Berglund, K. Johansson, and J. Philipsson. 2003. Genetic effects on stillbirth and calving difficulties in Swedish Holsteins at first and second calving. J. Dairy Sci. 86:2228-2235.

Van Pelt, M. L., and G. De Jong. 2012. Genetic analysis of calf survival in Dutch Holstein calves. Page 242 in Book of Abstracts 63rd Annu. Mtg. European Fed. Anim. Sci., Bratislava, Slovakia. Wageningen Academic Publishers, Wageningen, the Netherlands.

Weller, J. I., and D. Gianola. 1989. Models for genetic analysis of dystocia and calf mortality. J. Dairy Sci. 72:2633-2643. 